\title{
Changes in Extremes Indices over Japan Due to Global Warming Projected by a Global 20-km-mesh Atmospheric Model
}

\author{
Ryo Mizuta ${ }^{1}$ Takao Uchiyama ${ }^{2}$, Kenji Kamiguchi ${ }^{2}$, Akio Kitoh ${ }^{2}$ and Akira Noda ${ }^{2}$ \\ ${ }^{1}$ Advanced Earth Science and Technology Organization, MRI, Tsukuba, Japan \\ ${ }^{2}$ Meteorological Research Institute, Tsukuba, Japan
}

\begin{abstract}
Changes in indices of extremes between the presentday climate and a future warmer climate are projected over Japan using a global 20-km-mesh atmospheric model. Comparisons with observed data show that the indices on temperature extremes are represented well in the model, while less intense precipitation biases are found. In the future climate simulation around 2090, the number of frost days decreases by 20-45 days with larger decrease along the Sea of Japan than the other area. Growing season length increases about a month. Changes in the temperature extremes are not uniform over Japan, showing usefulness of projections using a high-resolution model. Although changes in precipitation extremes are small and not significant over a large part of Japan, statistically significant increase in indices of heavy precipitation is found in western part of Japan and Hokkaido.
\end{abstract}

\section{Introduction}

To evaluate the possible impacts of global warming upon the meteorological phenomena of small scales in time and space is important not only from the scientific but also from the socio-economic viewpoints. While possible changes in extreme events induced by global warming have been described in a report by the Intergovernmental Panel on Climate Change (IPCC 2001), the description remained qualitative, partly due to the limited resolution of the existing climate models. Even the directions of the projected changes were almost uncertain for some kinds of extreme events.

We have performed climate simulations for the present-day climate and a future climate using a $20-\mathrm{km}$ mesh global atmospheric general circulation model. To evaluate changes in extreme events, we use ten extremes indices for surface air temperature and precipitation proposed by Frich et al. (2002) and recommended for IPCC model standard output (http://wwwpcmdi.llnl.gov/ipcc/standard_output.html). In this study, the representation of the indices over Japan in the present-day climate simulation is verified using a dataset from very densely distributed observational systems, and changes in the indices simulated in the model are examined focusing on Japan. It is known that the regional climate around Japan is affected by tropical cyclones and Baiu frontal rainfalls in the Asian summer monsoon. These phenomena have not been simulated well by conventional climate models with a few hundreds of kilometer grid size on which regional models are nested. Here, we examine the present and the future regional climates by using a high-resolution global model capable of representing such phenomena.

\section{Model and methods}

The model used in this study is a prototype of the

Corresponding author: Ryo Mizuta, Advanced Earth Science and Technology Organization, Meteorological Research Institute, 1-1 Nagamine, Tsukuba, Ibaraki 305-0052, Japan. E-mail: rmizuta@mrijma.go.jp. (12005, the Meteorological Society of Japan. next generation global atmospheric model of the Japan Meteorological Agency. The simulations were performed at a resolution of TL959, which corresponds to a horizontal grid size of about $20 \mathrm{~km}$. The model uses 60 levels in the vertical with the model top at $0.1 \mathrm{hPa}$. A detailed description of the model is given in Mizuta et al. (2005).

We have performed two "time-slice" 10-year simulations: 1) a present-day climate simulation using the observed climatological sea surface temperature (SST) as a boundary condition, and 2) a global warming simulation forced by the climatological SST plus anomalies. The SST anomalies are the difference between the average from 1979 to 1998 in the 20th Century climate simulation and that from 2080 to 2099 in the SRES A1B scenario simulation using the MRI-CGCM2.3 (Yukimoto et al. 2005). The concentrations of $\mathrm{CO}_{2}$ are set to be constant at $348 \mathrm{ppmv}$ for the present-day climate and $659 \mathrm{ppmv}$ for the future climate. The change in the global-mean surface air temperature between the two simulations is $2.5 \mathrm{~K}$. It has been verified that the model can consistently simulate from a global-scale long-term mean climate to small-scale phenomena, such as tropical cyclones and Baiu fronts (Mizuta et al. 2005; Oouchi et al. 2005).

The temperature data of the present-day climate simulation is compared with the data obtained by the Automated Meteorological Data Acquisition System (AMeDAS) from 1981 to 2000. The AMeDAS is an automatic meteorological observing system set up throughout Japan. Temperature data observed at 850 points are used in this study. The precipitation data are compared with the radar-AMeDAS precipitation analysis from 1991 to 2000. Precipitation is estimated from observations of radars calibrated using the AMeDAS. Precipitation is observed by the system at about 1300 points, which are distributed with an average interval of $17 \mathrm{~km}$. The calibration algorithm is described in Makihara (1996).

We use extremes indices proposed by Frich et al. (2002). The definitions of the indices are listed in the Supplement 1. All the indices are calculated for each year, and the average over the whole period is used. As the base period for calculating the long-term averages or percentiles, we use here the whole period of the simulation or the data, while Frich et al. (2002) used 19611990.

\section{Simulating present-day climate}

\subsection{Temperature extremes}

Figures $1(\mathrm{a}-\mathrm{e})$ show the temperature-based extremes indices calculated using AMeDAS data, and Figs. $1(\mathrm{f}-\mathrm{j})$ show those calculated using the present-day climate simulation.

It is natural to expect that the annual mean surface air temperature (Tav) near the sea would be well simulated in the model because the observed SST is given as a boundary condition. The agreement is seen also over the inland area. Since the higher-wavenumber components of the topography are removed in the model, the altitude defined for each grid cell is lower than that in the real world in mountainous area, whereas the observational points are usually located on the troughs 

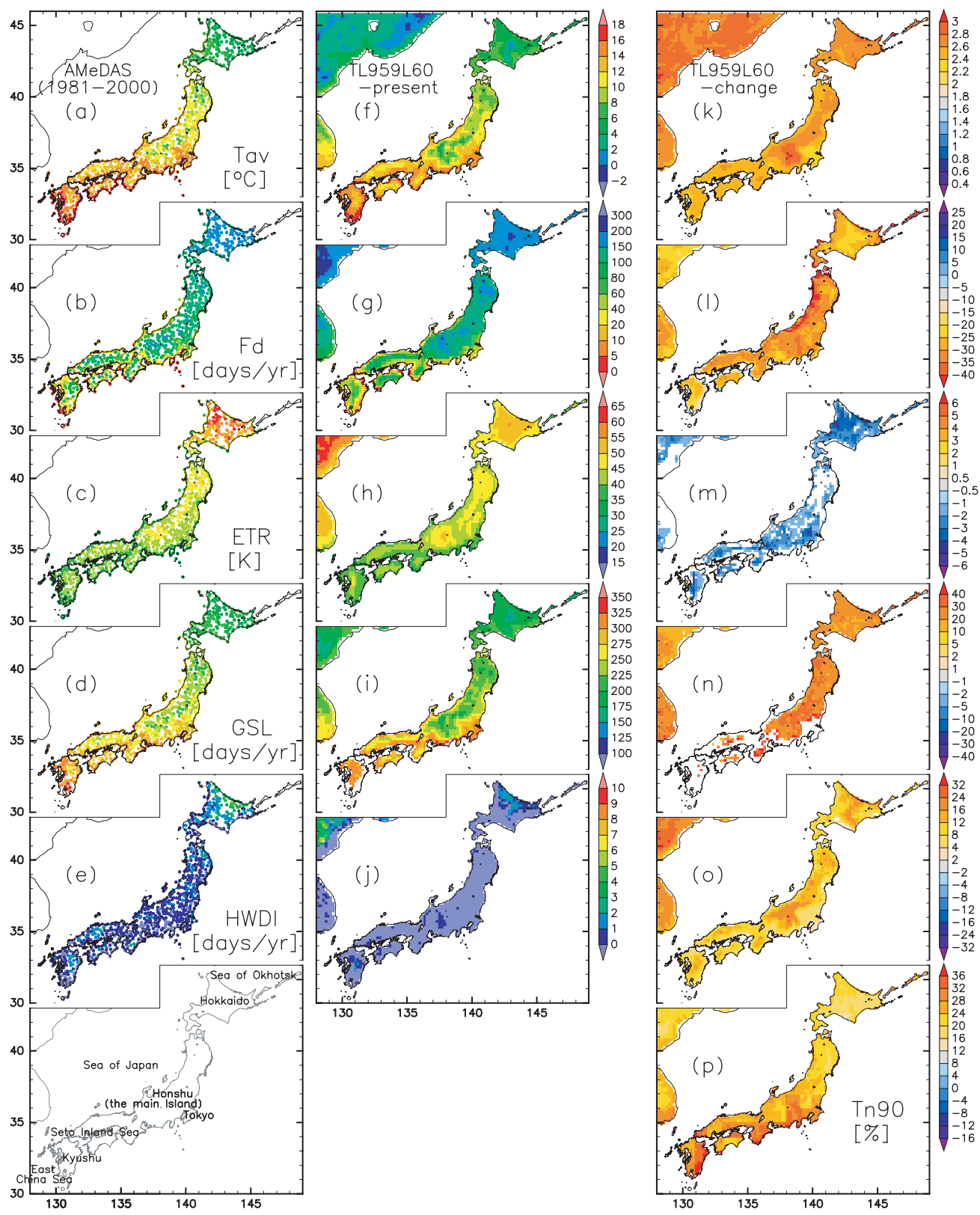

Fig. 1. Geographical distribution of the temperature-based extremes indices calculated using (a-e) AMeDAS data from 1981 to 2000 , $(\mathrm{f}-\mathrm{j})$ the present-day climate simulation, and $(\mathrm{k}-\mathrm{p})$ the change in the indices from the present-day simulation to the future climate simulation. The indices are calculated for each year, and the values averaged over the whole years are shown. The area where the difference is not $95 \%$ significant is not colored. The area where the index cannot be defined for all the years is also not colored in (n).

rather than crests. Therefore, the difference among the altitudes of the observational points and those of the corresponding model grids are not so large.

The total number of observed annual frost days $(\mathrm{Fd})$ is more than 150 days in Hokkaido and 40-150 days in the other regions, except that there are fewer than 5 days on the southern coastline. This feature is represented well in the model. The difference between annual maximum and minimum temperature (ETR) is about 10 $\mathrm{K}$ less than the observation in the interior of Hokkaido, as extremely cold minimum temperatures in winter are not likely to be represented well in the model. The length of the growing season (GSL), defined as the period between when daily mean temperature (Tday) over $5^{\circ} \mathrm{C}$ for longer than 5 days and when Tday under 5 ${ }^{\circ} \mathrm{C}$ for longer than 5 days, is simulated slightly shorter in the model than observed in the middle of Honshu. The bias of GSL averaged over Japan is about -15 days. The heat wave duration index (HWDI), which indicates maximum consecutive days with maximum temperature (Tmax) over $5 \mathrm{~K}$ higher than the long-term climatology of Tmax, is zero over most of Japan in the model, while it is about 0.7 days in the observation averaged over all the points. This means that continuous extreme temperature events are less likely to occur than in the observation. One reason is that the SSTs are prescribed at climatological values without inter-annual variation in the model.

\subsection{Precipitation extremes}

Figures $2(\mathrm{a}-\mathrm{c})$ show the precipitation-based extremes indices calculated using the radar-AMeDAS data, 

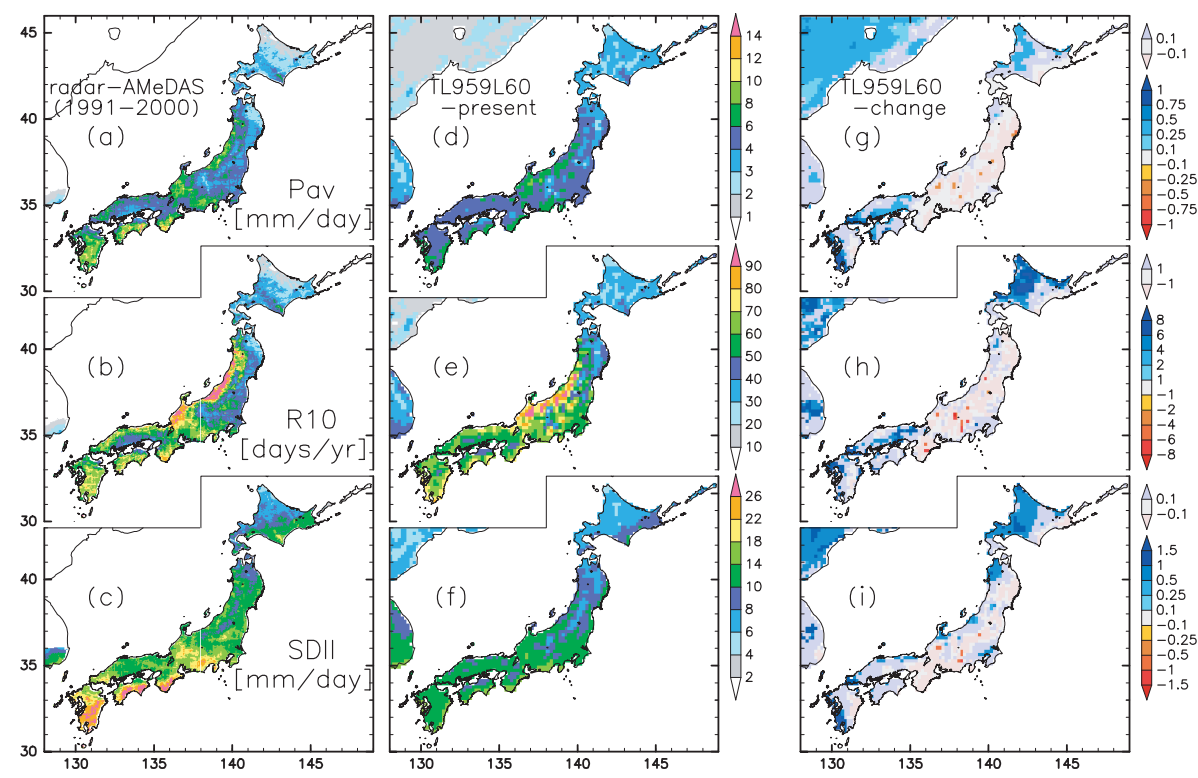

Fig. 2. Geographical distribution of the precipitation-based extremes indices calculated using (a-c) the radar-AMeDAS data from 1991 to 2000, (d-f) the present-day climate simulation, and (g-i) the change in the indices from the present-day simulation to the future climate simulation. The area where the difference is not 95\% significant is colored in light colors (the upper color bars).

and Figs. 2 (d-f) show those calculated using the present-day climate simulation. Among the indices proposed by Frich et al. (2002), we show only notable ones here and the other indices are shown in the Supplement 2. The annual mean precipitation (Pav) is underestimated in Kyushu and along the southern coast of Japan. This is due to the lack of precipitation in summer, when a large amount of precipitation is observed in the area. In winter, a large amount of snowfall is observed along the Sea of Japan due to steady winter monsoon northwesterlies blocked by the topography of the Japan Islands. The geographical distribution of precipitation around there is well simulated in the model, although the amount is underestimated as well.

The number of days with precipitation over $10 \mathrm{~mm}$ (R10) in the model agrees well with the observation. On the other hand, simple daily intensity (SDII) defined as the total precipitation divided by number of wet days are underestimated by about 30\%, while geographical characteristics are represented qualitatively. This is associated with a bias of the model that extremely heavy rains are not represented well and weak precipitations are more frequent than the observation. Underestimations of the other three indices in the Supplement 2 are consistent with the bias.

\section{Changes due to global warming}

In this section, we discuss changes in the indices described in the previous section. The statistical significance of the change is calculated using the Student's ttest. Note that, since the SSTs with no inter-annual variation are used, the t-test is based on the model climate which has less inter-annual variability.

\subsection{Temperature extremes}

Figures $1(\mathrm{k}-\mathrm{p})$ show the changes in the temperaturebased indices from the present-day simulation to the future climate simulation. The difference in the annualmean SST between the two experiments is $2-2.4 \mathrm{~K}$ around Japan, except for about $3 \mathrm{~K}$ in the Sea of Okhotsk. In accordance with the SST change, Tav increases by about $2.5 \mathrm{~K}$ over the Japan Islands. Larger changes in Tav are seen in Hokkaido and in the interior of northern Honshu. The increase in Tav is smaller over the plain around Tokyo than that in the other region. According to seasonal-mean values (not shown), the feature is attributable to the warming in winter. Generally, warming is larger when it is accompanied by a decrease in snow cover. Because of little snow cover in the vicinity of Tokyo, therefore, the change in Tav is smaller than that over the surrounding mountainous area. Note that the present model does not include the effects of urbanization.

Fd decreases by 20-45 days except on the southern coastline. The decrease is larger inside Honshu, and a decrease over 40 days is seen along the Japan Sea in northern Honshu. A global analysis shows that the increase of winter temperature is larger over the Eurasian continent as suggested in Fig. 1 (k), and meridional components of the winter monsoon northwesterlies are weakened. This can contribute to the decrease in $\mathrm{Fd}$ along the Japan Sea. Over the Eurasian continent of the figure, the decrease is not large, because changes of minimum temperature (Tmin) around $0^{\circ} \mathrm{C}$ affect the decrease in Fd and Tmin is much lower than $0^{\circ} \mathrm{C}$ in winter over the area.

ETR decreases in most regions over Japan. The decrease is seen in a large part of the extratropics in the northern hemisphere, and is consistent with the observed decreasing trend (e.g., Frich et al. 2002). The decrease is larger in Hokkaido. This is associated with the weakened intra-seasonal variation of minimum temperature in winter. On the other hand, the decrease of ETR is not significant along the coastline. In the future climate simulation, the SST difference between summer maximum and winter minimum is prescribed to increase around Japan. Therefore, ETR increases over the ocean near the Japan Islands (not shown), and the change in ETR is small near the coastline.

GSL increases by 20-40 days in almost all areas, and dependence on geographical characteristics is small over Japan. The index can be defined for all the years only in a limited area, because daily-mean temperature is always higher than $5^{\circ} \mathrm{C}$ in the lower latitudes.

The increase in HWDI in Japan is about 10-15 days. The absolute values and changes are both much smaller than those over the Eurasian continent. This characteristic is common to most islands in the world. Continuous 
high temperature events are infrequent over islands since the surface temperature is much affected by the SST surrounding them. The coastal areas of the Eurasian continent show larger increase under the influence of a very large increase in HWDI over the inland area of the continent.

The percentage of days in which the minimum temperature exceeds those of the long-term 90th percentile (Tn90), which is always $10 \%$ everywhere in the presentday climate, increases more in the lower latitudes. This is consistent with the global distribution of the change. In the lower latitudes, since the intra-seasonal variability of minimum temperatures is smaller, the value of the 90th percentile is closer to the average. Therefore, even if the change in average minimum temperature is the same, Tn90 increases more in the lower latitudes. For the same reason, if the inter-annual variations of the SSTs are included, it is expected that the increase of Tn90 would be less due to larger variability of Tmin. Note that a box-wise pattern seen in Fig. 1 (p) is the effect of the 1-degree-mesh vegetation type map used as a boundary condition.

\subsection{Precipitation extremes}

Figures $2(\mathrm{~g}-\mathrm{i})$ show the changes in the precipitationbased indices from the present-day simulation to the future climate simulation. The areas in which the difference is not significant at $95 \%$ level by the Student's ttest are shown in light colors. Statistically significant increases of Pav are found in Kyushu along the East China Sea, near the Seto Inland Sea, and in part of Hokkaido. Increases of R10 and SDII are also seen in the almost same regions. While apparent seasonality is not found in Hokkaido, large changes in the indices are seen in the western part of Japan in July. The latter changes are related with the change in the Baiu frontal rainfall. Yoshizaki et al. (2005) showed that the number of the rainfall systems which develop rapidly to bring heavy precipitation increases in July in a warmer climate.

However, as a whole, the differences of the indices including Pav are small between the two experiments and not significant over a large part of Japan, while statistically significant changes in Pav, R10, and SDII are widely seen over inland areas of the continents. This suggests we need simulations longer than 10 years to warrant a comparison of the two results around Japan.

\section{Concluding remarks}

Changes in the extremes indices recommended for the upcoming IPCC report are examined over Japan using a global $20-\mathrm{km}$-mesh atmospheric model. The temperature-based extremes indices are represented well in the model. Corresponding to an increase in Tav, decreases in Fd and ETR, and increases in GSL, HWDI, and Tn90 are seen over Japan. Increases of the precipitationbased indices, R10 and SDII, as well as Pav, are found in western Japan and Hokkaido. However, the changes in precipitation-based indices are generally small and not significant over a large part of Japan. The present analysis has revealed that the model has a room for improvement in representing extremes in precipitation which have fine spatial and temporal scales. For the improvements, a more realistic representation of presentday mean precipitation in such a fine scale is required.

The high-resolution global model has a potential advantage over regional climate models (RCMs) of the same resolution in that the global model can resolve such phenomena as tropical cyclones and a detailed structure of the Baiu front. Meanwhile, RCMs may also possibly obtain more realistic representations since they can optimize the physical parameterizations so as to well reproduce the regional climate around the specific region. Comparisons of extreme indices between our model and RCMs under the same experimental condi- tions are left for a future work.

Usually, global warming projections have been performed using global models with hundreds of kilometers grid size. As we have shown here, geographical distributions affected by small-scale topography as fine as those by RCMs are represented globally by our model. This fact clearly indicates the usefulness of global projections using a $20-\mathrm{km}$-mesh high-resolution model. Even though there are many reservations that should be remedied in future work, this experiment is the first attempt to use a global model for the projection of extreme events due to global warming with a resolution as high as that attained only by conventional regional models. Global distributions of changes in the temperature-based and precipitation-based extremes indices will be reported in separate publications.

\section{Acknowledgments}

This work was based on the results of experiments performed by the global modeling group under the framework of the "Kyosei Project 4: Development of Super High-Resolution Global and Regional Climate M odels" supported by the Ministry of Education, Culture, Sports, Science and Technology (MEXT). The simulations are carried out on the Earth Simulator. The figures were produced using the GFD-Dennou Library. We are grateful to Prof. M. Kimoto and two anonymous reviewers for helpful comments.

\section{Comments and supplments}

The definitions of the extremes indices are listed in Supplement 1. Geographical distributions of the precipitation-based indices that are not shown in Fig. 2 are presented in Supplement 2.

\section{References}

Frich, P., L. V. Alexander, P. Della-Manta, B. Gleason, M. Haylock, A. M. G. Klein Tank and T. Peterson, 2002: Observed coherent changes in climatic extremes during the second half of the twentieth century. Clim. Res., 19, 193-212.

IPCC, 2001: Climate change 2001. The scientific basis. Contribution of Working Group I to the Third Assessment Report of the Intergovernmental Panel on Climate Change. [Houghton, J. T., Y. Ding, D. J. Griggs, M. Noguer, P. J. van der Linden, X. Dai, K. Maskell and C. A. Johnson (eds.)]. Cambridge University Press, Cambridge, UK and New York, NY, USA, 881pp.

Makihara, Y., 1996: A method for improving radar estimates of precipitation by comparing data from radars and raingauges. J. Meteor. Soc. Japan, 74, 459-480.

Mizuta, R., K. Oouchi, H. Yoshimura, A. Noda, K. Katayama, S. Yukimoto, M. Hosaka, S. Kusunoki, H. Kawai and M. Nakagawa, 2005: 20km-mesh global climate simulations using JMA-GSM model. J. Meteor. Soc. Japan, (submitted).

Oouchi, K., J. Yoshimura, H. Yoshimura, R. Mizuta, S. Kusunoki and A. Noda, 2005: Tropical cyclone climatology in a global-warming climate as simulated in a $20 \mathrm{~km}-\mathrm{mesh}$ global atmospheric model. J. Meteor. Soc. Japan, (submitted).

Yoshizaki, M., C. Muroi, S. Kanada, Y. Wakazuki, K. Yasunaga, A. Hashimoto, T. Kato, K. Kurihara, A. Noda and S. Kusunoki, 2005: Changes of Baiu (Mei-yu) frontal activity in the global warming climate simulated by a nonhydrostatic regional model. SOLA, doi:10.2151/sola. 2005-008.

Yukimoto, S., A. Noda, T. Uchiyama, S. Kusunoki and A. Kitoh, 2005: Climate changes of the twentieth through twentyfirst centuries simulated by the MRI-CGCM2. 3. Pap. Meteor. Geophys. in press.

Manuscript received 27 April 2005, accepted 1 August 2005

SOLA: http://www.jstage.jst.go.jp/browse/sola/ 